\title{
A SUSTENTAÇÃO dOS PREÇOS AGRÍCOLAS CATARINENSES NO PERIOODO 1997-2011: UMA ANÁLISE DOS CONTRATOS DE OPÇÃO DE VENDA (COV)
}

\author{
Angélica Massuquetti \\ Marilise Dorneles Spat ${ }^{2}$ \\ Pedro Henrique de Morais Campetti ${ }^{3}$ \\ Juliano Luiz Koch ${ }^{4}$ \\ Rafaela Lauffer Ostermann Tamiosso ${ }^{5}$
}

\begin{abstract}
Resumo
O objetivo do artigo é analisar os Contratos de Opção de Venda (COV) como um instrumento para a sustentação dos preços agrícolas no estado de Santa Catarina no período 1997-2011. A metodologia empregada foi a pesquisa bibliográfica e a coleta de informações na base de dados da CONAB. Os resultados mostraram que, no período em questão, o estado teve participação ativa nas negociações dos COV ofertados pelo Governo Federal em quase todos os anos, todavia, com valores não tão expressivos quando comparados a outros estados da federação. No que diz respeito ao arroz, verificou-se que os COV são um instrumento da PGPM capaz de assegurar a manutenção dos preços.
\end{abstract}

Palavras-chave: COV; PGPM; Garantia de Preços Agrícolas.

Classificação JEL: Q1; Q11; Q18.

Professora do Programa de Pós-Graduação em Economia (PPGE) da Universidade do Vale do Rio dos Sinos (UNISINOS) e Doutora em Desenvolvimento, Agricultura e Sociedade pela Universidade Federal Rural do Rio de Janeiro (UFRRJ). Endereço eletrônico: angelicam@unisinos.br

Mestranda do Programa de Pós-Graduação em Economia (PPGE) da Universidade do Vale do Rio dos Sinos (UNISINOS) e Economista pela Universidade Federal de Santa Maria (UFSM). Endereço eletrônico: marilisespat@ yahoo.com.br

Mestrando do Programa de Pós-Graduação em Economia (PPGE) da Universidade do Vale do Rio dos Sinos (UNISINOS) e Economista pela UNISINOS. Endereço eletrônico: pedro campetti@yahoo.com.br

Aluno do Curso de Ciências Econômicas da Universidade do Vale do Rio dos Sinos (UNISINOS) e Bolsista de Iniciação Científica UNIBIC-UNISINOS. Endereço eletrônico: julianoo.koch@gmail.com

5 Aluna Curso de Ciências Econômicas da Universidade do Vale do Rio dos Sinos (UNISINOS) e Bolsista de Iniciação Científica PROBIC-FAPERGS/UNISINOS. Endereço eletrônico: rafaelaostermann@gmail.com 
Angélica Massuquetti - Marilise Dorneles Spat • Pedro Henrique de Morais Campetti

Juliano Luiz Koch • Rafaela Lauffer Ostermann Tamiosso

\section{INTRODUÇÃO}

A Política de Garantia de Preços Mínimos (PGPM) ganhou importância a partir dos anos oitenta em razão das dificuldades apresentadas pelo crédito rural no final da década anterior, com a redução dos recursos e dos subsídios devido ao processo de aceleração da inflação e a consequente necessidade de uma política mais restritiva por parte do Governo Federal. A administração dos recursos escassos para o financiamento da atividade agrícola obrigou o Governo Federal a ter uma atuação por produto e não mais sobre o setor agrícola como um todo. Os Empréstimos do Governo Federal Com Opção de Venda (EGF-COV), nesse sentido, tornaram-se um dos principais instrumentos utilizados na condução da política agrícola nacional, com o intuito de interferir diretamente na produção e na comercialização e, consequentemente, no crescimento e na modernização do setor.

No entanto, em razão da necessidade de adequar a política agrícola brasileira à realidade econômica do país na década de 1990 - redução dos recursos oriundos do Tesouro Nacional e abertura econômica-, o EGF-COV foi extinto a partir da safra agrícola 1996/1997 e criou-se um instrumento complementar à PGPM para promover a sustentação dos preços agrícolas: os Contratos de Opção de Venda (COV). De acordo com Gasques e Spolador (2003), a política de preços mínimos, sendo uma política de suporte de preços, por um lado, tem o objetivo de diminuir os riscos de variações de preços dos produtos agrícolas e também garantir a renda dos produtores rurais e, por outro, reduzir os efeitos que as variações dos preços agrícolas têm sobre a determinação do Índice Geral de Preços (IGP).

O objetivo do artigo é analisar os COV como um instrumento para a sustentação dos preços agrícolas no estado de Santa Catarina no período 1997-2011, numa estratégia de redução da intervenção estatal no processo de comercialização agrícola e de ampliação do volume de recursos privados no financiamento dessa atividade. Os Contratos oferecem ao produtor rural o direito de vender o seu produto para o Governo, numa data futura e com o preço prefixado.

Esta pesquisa justifica-se pela importância do agronegócio para a economia catarinense. Os principais produtos agropecuários exportados pelo estado são as carnes de frango e suína, o fumo e a soja e os principais grãos produzidos são o trigo, o arroz, o feijão, o milho e a soja, sendo que 
A sustentação dos preços agrícolas catarinenses no período 1997-20 I I: uma análise dos contratos de opção de venda (COV)

Santa Catarina é o segundo maior produtor de arroz do país. O cultivo de arroz irrigado em Santa Catarina é divido por todo o estado: no alto, médio e baixo Vale do Itajaí, no litoral norte e na região sul. Essas regiões somam uma área total de 150.000 hectares. Santa Catarina tem como principal produto produzido o arroz parabolizado, onde seu comércio é feito com os estados do Paraná, de São Paulo e do Rio de Janeiro. É esperada, para a safra 2011/2012, uma ampliação de 6,38\% no rendimento desta cultura, passando de $6.488 \mathrm{~kg} / \mathrm{ha}$, na safra 2010/2011, para $6.931 \mathrm{~kg} / \mathrm{ha}$. A importância desta commodity reflete-se na estrutura que é organizada para a manutenção da estabilidade de seus preços (EPAGRI, 2012a; 2012b).

As informações relativas ao funcionamento e à relevância dos COV no conjunto de instrumentos utilizados na política de intervenção no mercado de produtos agrícolas foram obtidas por meio da investigação da produção do conhecimento desenvolvida a respeito desse tema e de dados da Companhia Nacional de Abastecimento (CONAB). Por fim, este estudo está dividido em três seções, além da introdução e das considerações finais: na segunda, foram apresentados os principais aspectos da PGPM; na terceira, foram analisados os COV como instrumento de seguro de preços; e, por fim, na quarta, foram analisados os COV, no período 1997-2011, no Brasil e, especialmente, em Santa Catarina.

\section{A POLÍtiCA DE GARANTIA DE PREÇOS MÍNIMOS NO BRASIL}

Segundo Delgado (1978), o primeiro órgão governamental criado com o propósito de definir e dirigir a política de preços mínimos para a agricultura brasileira foi a Comissão de Financiamento da Produção (CFP), subordinada ao Ministério da Fazenda (Decreto-Lei 5.212, de 23.01.1943). Porém, apenas em 1951 é que se estabeleceu uma política efetiva de preços mínimos, em que os produtores e as cooperativas eram os que, preferencialmente, usufruíam desse benefício.

A CFP era responsável pelo financiamento ou aquisição de gêneros, bem como pelo seu armazenamento, conservação e identificação das mercadorias. Todos os gêneros adquiridos pelo Governo Federal deveriam ser destinados ao mercado interno, como reguladores ou estoque de reservas, ou ao mercado externo, pela exportação dos excedentes. Os recursos para 
execução dessa lei eram oriundos de um fundo formado através das operações realizadas pela própria CFP. Foi constatado que, entre os anos de 1951 e 1961, os principais beneficiados com a política de preços mínimos estavam sendo os beneficiadores, exportadores, comerciantes e industriais. Procurou-se, dessa forma, tentar impedir a participação desses segmentos nos benefícios da PGPM, facilitando, assim, a participação dos agricultores e das cooperativas. Para Duarte (1987, p. 6), a PGPM “[...] visa minimizar efeitos depressivos de cotações externas, de produtos exportáveis, sobre a produção nacional e, no caso de alimentos básicos, estimular o aumento da produção para atender ao mercado interno e formar estoques de reserva".

As Leis 6 e 7, assinadas em 26.09.1962, criaram a Companhia Brasileira de Alimentos (COBAL) e a Companhia Brasileira de Armazenamento (CIBRAZEM). A COBAL e a CIBRAZEM, juntamente com a Superintendência Nacional de Abastecimento (SUNAB), que era encarregada do controle dos preços, integravam parte do Sistema Nacional de Abastecimento. Nesse período, verificaram-se outras modificações da PGPM, como a introdução de indexação dos preços mínimos em virtude da inflação e a introdução da pecuária na política. Em 1964, a Lei 4.595, de 31.12.1964, que tratava da política e instituições monetárias, bancárias, creditícias e que criou o Conselho Monetário Nacional (CMN), estabeleceu que o Banco do Brasil seria o executor da política de preços mínimos dos produtos agropastoris, além de financiar a aquisição e a instalação da pequena e média propriedade. A partir do Decreto-Lei 57.391, de 07.12.1965, os beneficiadores, exportadores, comerciantes e industriais voltaram a integrar efetivamente a política de preços mínimos.

A PGPM foi criada valendo-se dos Empréstimos do Governo Federal (EGF) e das Aquisições do Governo Federal (AGF). Por sua vez, o mecanismo EGF podia ser dividido em Empréstimos do Governo Federal com Opção de Venda ao Governo (EGF-COV) e Empréstimos do Governo Federal sem Opção de Venda ao Governo (EGF-SOV). Tanto no caso do AGF, quanto do EGF, a demanda por esses mecanismos atuava de acordo com as expectativas dos preços futuros dos produtos (descontados os custos com armazenagem), os preços atuais e os preços mínimos. Segundo Oliveira (1977), o EGF é um instrumento de financiamento dos Estoques Reguladores. Já o AGF é um mecanismo que garante os preços mínimos aos produtores rurais, além de ser por intermédio dele que as compras da CFP 
A sustentação dos preços agrícolas catarinenses no período 1997-20 I I : uma análise dos contratos de opção de venda (COV)

são feitas e de financiar a formação dos Estoques de Segurança, regulando a oferta e a demanda do setor, comprando ou vendendo de acordo com as necessidades do mercado.

Duran (1978, p.145) identificou algumas modificações importantes ocorridas no programa de preços mínimos, no período 1967-1971, como se pode observar:

[...] o preço mínimo passou a ser fixado por zonas dentro de cada estado; sua fixação passou a ser feita excluindo impostos, juros, comissões e custos de estocagem; os preços mínimos passaram a ser fixados sistematicamente para as Regiões Norte e Nordeste; passaram a ser anunciados pelo menos três meses antes da época do plantio. A orientação geral deste período foi dar à política um papel de longo prazo, em lugar de contentarse apenas em influenciar a produção a curto prazo, através de um preço mínimo relativamente alto que poderia ser reduzido no ano seguinte se a oferta fosse abundante.

A evolução dos empréstimos deu-se de forma contínua até 1976 graças ao crescimento dos preços mínimos e ao incentivo às exportações. De 1976 a 1979, observou-se uma redução nos empréstimos em virtude da queda nos preços mínimos e da queda dos subsídios, que desestimulou a demanda por EGF. O fim da década de 1970 e o início da década seguinte representaram um novo crescimento aos empréstimos devido à recuperação do nível de preços mínimos e à elevação dos subsídios. A existência dos subsídios sempre foi um fator de grande estímulo à tomada desses empréstimos (MOLLO, 1983).

Alguns resultados da aplicação da política de preços mínimos foram observados por Pinto (1980):

a) Os intermediários (maquinistas, beneficiadores, industriais e outros) são os principais beneficiários da PGPM, no entanto são os que nada arriscam no processo produtivo, sendo uma das maiores distorções;

b) As operações de contratação de EGF ou AGF tornam-se inviáveis para o pequeno produtor rural devido às exigências necessárias, tais como transporte, classificação e armazenagem da produção nos pontos designados pelo Banco do Brasil, desta forma, apenas os intermediários, as cooperativas e alguns grandes produtores utilizam este instrumento; 
c) Existe a concentração por produto: algodão, arroz e soja absorveram, nos últimos dez anos (década de 1970), entre $70 \%$ e $80 \%$ do total das aplicações; e

d) A distribuição é concentrada em favor das regiões Centro/Sul e em prejuízo das regiões Norte/Nordeste.

Com a redução dos recursos oriundos do Tesouro Nacional e dos subsídios para o financiamento da atividade agrícola na década de 1980, a PGPM foi o instrumento utilizado pelo Governo Federal para assegurar os preços recebidos pelos produtores rurais e garantir a rentabilidade do setor. Para que esse papel mais ativo da PGPM fosse cumprido, várias modificações foram introduzidas nessa política, como se pode observar no Quadro 1.

Quadro 1: Principais modificações na Política de Garantia de Preços Mínimos na década de $1980^{6}$

\begin{tabular}{|c|c|l|}
\hline SAFRA & LEGISLAÇÃO & \multicolumn{1}{c|}{ PRINCIPAIS ALTERAÇÕES } \\
\hline $1979 / 1980$ & $\begin{array}{c}\text { Voto do CMN } \\
155 / 79, \text { de } \\
16.05 .1979\end{array}$ & $\begin{array}{l}\text { Com a criação do Valor Básico de Custeio (VBC) } \\
\text { que passa a vigorar na Safra 1979/80, os preços } \\
\text { mínimos deixarão de ser parâmetros para os orça- } \\
\text { mentos dos empréstimos de custeio. }\end{array}$ \\
\hline $1981 / 1982$ & --- & $\begin{array}{l}\text { Estabelecimento de Preços-Base, reajustados pelo } \\
\text { INPC até o início da comercialização dos produtos. }\end{array}$ \\
\hline $1985 / 1986$ & --- & $\begin{array}{l}\text { O período de correção do Preço-Base é alterado. } \\
\text { Deu-se tratamento preferencial para o arroz, man- } \\
\text { dioca, milho e sorgo, cujos períodos de correção } \\
\text { foram estendidos em dois meses. }\end{array}$ \\
\hline $1986 / 1987$ & $\begin{array}{l}\text { Decreto 93118, } \\
\text { de 14.08.1986 }\end{array}$ & $\begin{array}{l}\text { Criação da regra de plurianualidade de preços } \\
\text { mínimos para as culturas de arroz, milho, sorgo, } \\
\text { mandioca e feijão. Esta regra não se aplica a pro- } \\
\text { dutos de exportação como soja, amendoim, algo- } \\
\text { dão e mamona. Para estes, foram levadas em con- } \\
\text { sideração as cotações do mercado internacional. }\end{array}$ \\
\hline
\end{tabular}

6 Para maiores informações ver Cezar (1990), Garcia e Fürstenau (1992), Massuquetti (2000), Massuquetti et al. (2009), Rezende (1988), Silva (1992a) e Silva (1992b). 
A sustentação dos preços agrícolas catarinenses no período |997-20 I I : uma análise dos contratos de opção de venda (COV)

\begin{tabular}{|c|c|l|}
\hline $1987 / 1988$ & $\begin{array}{c}\text { Portaria MA 36, } \\
\text { de 22.02.1988 }\end{array}$ & $\begin{array}{l}\text { Criação do preço de intervenção cujo mecanismo } \\
\text { consiste numa faixa de variação de preços onde o } \\
\text { limite inferior e o preço mínimo o o superior e o } \\
\text { preço de intervenção, a partir do qual o Governo } \\
\text { passa a vender sus estoques. Admite-se que no } \\
\text { espaço entre o preço mínimo e o preço de inter- } \\
\text { venção deve atuar o mercado. Correção do Preço } \\
\text {-Base durante todo o período da colheita. }\end{array}$ \\
\hline $1988 / 1989$ & $\begin{array}{c}\text { Portaria MA 123, } \\
\text { de 10.06.1988 }\end{array}$ & $\begin{array}{l}\text { Introduz o sistema de correção de preços de inter- } \\
\text { venção pela OTN fiscal para arroz, feijão e milho. }\end{array}$ \\
\hline
\end{tabular}

Fonte: Gasques e Verde (1990, p.20).

De acordo com Gasques e Spolador (2003, p. 18), a PGPM, através da AGF e do EGF, foi um importante instrumento empregado na expansão da fronteira agrícola brasileira:

Atribui-se aos EGF importância na formação e na expansão da agroindústria. No caso da expansão da fronteira, as AGF representavam um subsídio do governo ao custo de transporte, já que uma agência oficial - a Companhia de Financiamento da Produção (CFP) - transportava os produtos adquiridos na fronteira para os centros consumidores do país. Milho e arroz, nas regiões de Goiás e de Mato Grosso, beneficiaram-se muito dessa política. Outro papel que a PGPM teve no desenvolvimento dessas novas regiões foi ter atuado como mecanismo de compensação pela escassez ou pela redução dos recursos do Crédito Rural. Esse fato foi marcante a partir de 1985. A Política de Preço Nacional Equalizado atuou complementando a ação da PGPM na fronteira, e a política de preço nacional equalizado para os combustíveis, a qual, sem dúvida, foi essencial para a expansão das áreas mais longínquas.

A redução da participação do Governo Federal no financiamento da agricultura foi a estratégia utilizada a partir de 1990. O processo de liberalização do mercado agrícola tinha o objetivo, segundo a política do Governo Federal, de reduzir o seu papel e, consequentemente, os recursos do Tesouro no financiamento da atividade, e tornar a agricultura brasileira mais competitiva no mercado mundial. Imaginava-se que os problemas da agricultura seriam resolvidos por intermédio de uma política liberal de comércio. A 
deficiência estatal na infraestrutura de armazenamento e de escoamento era motivo de sustentação para que a iniciativa privada passasse a ocupar esse espaço. O Governo Federal pretendia atuar apenas no sentido de não prejudicar o abastecimento interno (BLECHER, 1990).

Algumas medidas foram adotadas, cujos objetivos eram a redução da participação do Governo Federal no setor agrícola, como a criação da CONAB, a partir da união da CFP, da CIBRAZEM e da COBAL, a extinção do Instituto do Açúcar e do Álcool (IAA), do Instituto Brasileiro do Café (IBC), da Empresa Brasileira de Extensão Rural (EMBRATER) e do Banco Nacional de Crédito Cooperativo (BNCC). Em relação a PGPM, uma das principais reformulações que ocorreram entre 1990-1994 foi a volta da regionalização dos preços mínimos para a safra 1990/1991, que havia sido suspensa desde 1979. A regionalização foi interrompida na safra 1991/1992 e reintroduzida na safra 1993/1994. Além disso, a própria criação do Prêmio de Liquidação do Empréstimo do Governo Federal (EGF especial), através da Portaria Interministerial 657, de 10.07.1991, foi outra reformulação importante na PGPM.

Em virtude das restrições financeiras do Governo, impostas pelo cenário nacional de crise financeira, a PGPM passou a selecionar e direcionar a sua atuação de forma mais restrita a partir de 1996. Foram criados programas especiais de compras, cujo objetivo era a garantia de preços mínimos aos pequenos produtores de regiões mais carentes em relação à infraestrutura $\mathrm{e}$ distância dos centros consumidores. A criação, pela CONAB, do Programa de Escoamento da Produção (PEP), no segundo semestre de 1996, fazia parte da nova realidade econômica vivida pelo Governo, de redução dos recursos para a agricultura.

Porto Neto (1996) chamou a atenção para a forma como o Governo passou a conduzir a política agrícola, destacando que o mesmo adotou dois tipos de medidas: transição e longo prazo. Entre as medidas de transição está a reformulação da PGPM, do crédito rural, dos estoques do Governo e do programa de seguro rural. Essas medidas de transição buscaram adaptar os instrumentos de política agrícola à realidade de uma economia menos intervencionista e mais voltada para o mercado. Por outro lado, as medidas de longo prazo reduziram o papel do Governo na regulação dos mercados. Entre as medidas de longo prazo podem-se citar: 
A sustentação dos preços agrícolas catarinenses no período |997-20 I I : uma análise dos contratos de opção de venda (COV)

[...] reestruturação e fortalecimento do sistema de pesquisa e difusão de tecnologias, expansão, diversificação e modernização da infra-estrutura portuária e de transportes, reestruturação e fortalecimento do sistema de defesa agropecuária e a criação de mecanismos para facilitar e ampliar a participação do setor privado na comercialização (PORTO NETO, 1996, p.10).

Na safra de 1996/1997, ocorreram algumas alterações na política agrícola, que tinham o intuito de tornar a atividade agrícola mais competitiva no mercado interno (em relação aos produtos que estavam sendo importados) e no mercado externo (com a possibilidade de conquista de novos mercados), como essas citadas por Massuquetti (1998, p. 127):

[...] tratamento especial em relação às taxas de juros, redução para zero da alíquota sobre Operações Financeiras (IOF) nos recursos externos captados para serem aplicados no setor agroindustrial e nas operações de crédito destinadas à comercialização agrícola, mudanças nos encargos financeiros do PROAGRO, desoneração do ICMS sobre as exportações de produtos primários e semi-elaborados, sobre a aquisição de bens de capital e sobre a utilização de energia para fins produtivos [...].

Também em relação à safra agrícola de 1996/1997, Franca e Freitas (1998) abordaram alguns aspectos que consideraram positivos (ou negativos) no que diz respeito ao plano de safra proposto nesse período, como se percebe nesta passagem:

[...] como pontos positivos a redução da taxa de juros de $16 \%$ para $12 \%$ ao ano nos créditos de custeio feitos com recursos controlados de crédito rural, a redução significativa das taxas de PROAGRO para lavouras conduzidas em áreas consideradas adequadas pelo zoneamento da EMBRAPA e o aumento da disponibilidade de recursos para a agricultura familiar através do PRONAF (Programa Nacional de Agricultura Familiar). No curto prazo, foram aspectos negativos, do ponto de vista do agricultor, uma vez que tornam a comercialização mais arriscada, as extinções: (a) da equivalência-produto nos financiamentos de custeio (atualmente restritos aos contratos 
via PRONAF), (b) dos Empréstimos do Governo Federal Com Opção de Venda (EGF-COV) e, (c) da transformação automática dos créditos de custeio em Empréstimos do Governo Federal Sem Opção de Venda (EGF-SOV) - por ocasião do vencimento do prazo de financiamento de custeio. Para reduzir esse grau de risco e facilitar a manutenção dos estoques governamentais foram criados os Contratos de Opção como instrumento complementar à Política de Garantia de Preços Mínimos (PGPM) para promover a sustentação dos preços agrícolas.

Segundo Turra (1997, p.34), uma das semelhanças entre os COV e o EGF-COV é a garantia de preço futuro, no entanto,

[...] ao contrário do EGF/COV, que além do preço de liquidação oferece um empréstimo para comercialização, o contrato de opção não está vinculado a qualquer financiamento de capital de giro para a comercialização. Do ponto de vista da dinâmica macroeconômica atual este mecanismo tem características que o tornam mais adequado às novas exigências mercadológicas de uma economia aberta à competição internacional, como é a brasileira atualmente. Essa suposta modernidade está vinculada ao fato que a participação dos agricultores nesse programa depende de sua própria iniciativa e de sua disposição em competir num leilão público pagando o prêmio associado a cada contrato arrematado. Essas exigências obrigam ao interessado conhecer as condições gerais de comercialização de seu produto e formar uma expectativa futura de preços que indique a conveniência, ou não, de envolver-se no programa. No caso do EGF/COV, essa necessidade de conhecer o comportamento de mercado não se tratava de um fator relevante na decisão do interessado visto que não era preciso pagar qualquer prêmio para participar do programa.

A partir desse período, portanto, os Contratos de Opção de Venda tornaram-se um dos instrumentos utilizados, pelo Governo Federal, para dar sustentação à PGPM e fundamentados na lógica de uma menor intervenção estatal. Na próxima seção serão abordados os COV, compreendidos como um seguro de preços para o produtor e um sinalizador de preços para o mercado. 
A sustentação dos preços agrícolas catarinenses no período 1997-20 I I : uma análise dos contratos de opção de venda (COV)

\section{OS CONTRATOS DE OPÇÃO DE VENDA COMO INSTRU- MENTO DE SEGURO DE PREÇOS}

Em razão da crescente necessidade de adequar as políticas agrícolas à realidade das políticas macroeconômicas, o Governo Federal, por meio do Ministério da Agricultura, propôs a criação dos Contratos, aprovados pelo Conselho Monetário Nacional através do Voto CMN 45, de 28.02.1995. Os COV foram lançados a partir da safra 1996/1997, regulamentados pelo Regulamento de Venda de COV de Produtos Agropecuários nº 001/1997, publicado no DOU de 28.02.1997 e implantados inicialmente na comercialização do milho.

Esse mecanismo de sustentação dos preços agrícolas foi empregado pelo Governo como um complemento da PGPM em razão da escassez de recursos públicos para compra ou estocagem da produção e garantia dos preços mínimos. Assim, os COV permitem que os produtores ou as cooperativas tenham a certeza de que seu produto pode ser vendido, no futuro, a um preço superior ao mínimo e previamente conhecido. Com essa garantia, produtores e cooperativas podem buscar um preço melhor no mercado e têm uma maior facilidade para obtenção de financiamentos no setor bancário para estocagem da produção até o momento adequado para a venda. A sustentação de preços por meio desse instrumento de comercialização busca reduzir as incertezas para o produtor (CONAB, 2009a).

De acordo com Campos (2007), a atenção aos preços de produtos agropecuários e suas oscilações é um importante instrumento para a formulação de políticas direcionadas ao setor rural, já que a flutuação cíclica desses preços provoca instabilidade da renda dos produtores e das despesas dos consumidores e estímulo ou desestímulo à produção. Para o autor,

\footnotetext{
O mercado agropecuário está sujeito a grandes variações de preços dos produtos ocasionadas por fatores naturais e econômicos, tais como dificuldades impostas ao planejamento da produção, instabilidade no abastecimento, em decorrência de perdas em períodos de intensa estiagem ou chuvas, e as flutuações nos índices de preços, em razão de queda ou intensidade da colheita, de oscilações das cotações nos mercados internacionais e da variabilidade cambial (CAMPOS, 2007, p. 323).
} 
Assim, os COV são um instrumento de seguro de preços, adquirido por produtores e cooperativas, dando a esses agentes o direito (e não a obrigação) de vender o produto ao Governo Federal (data futura e preço fixado previamente). O objetivo é proteger os agentes contra possíveis riscos de redução dos preços dos produtos. Os Contratos são utilizados quando o preço mínimo está acima do preço de mercado e há interesse do governo em garantir renda ao produtor e produção suficiente para abastecer o mercado interno (CONAB, 2009a).

De acordo com Cruz e Teixeira (2006, p. 27-28),

\begin{abstract}
No momento de adesão ao COV o produtor faz uma comparação entre o preço mínimo, o preço de mercado e o preço de exercício definido para o contrato. Desse modo, somente demandará um COV caso o preço de exercício seja superior aos outros preços. Por sua vez, à época de vencimento dos contratos de opção de venda, a expectativa é de que quanto mais próximos estiverem os preços de mercado e os preços de exercício, menor o número de contratos de opção exercido pelos produtores. Ou seja, quanto maior a razão entre o preço de mercado e o preço de exercício, mais eficaz terá sido o COV. Isso porque, uma vez adquirido o $\mathrm{COV}$, o intuito da política de garantia de preço ao produtor se efetivará se o produtor não exercer seu direito de venda ao governo. Por um lado, o Estado fica livre dos custos ligados à armazenagem da produção e, por outro lado, o produtor terá obtido um preço de mercado satisfatório.
\end{abstract}

As negociações dos Contratos oferecidos pelo governo são realizadas por corretores, que representam os produtores e/ou cooperativas, em Bolsas de Cereais, de Mercadorias ou de Futuros. Os leilões públicos ocorrem através do Sistema Eletrônico de Comercialização (SEC) da CONAB e os Contratos são adquiridos pelos lances de maior valor para os prêmios. O prêmio é o valor pago pelo produtor e/ou cooperativa para a aquisição de um direito de vender ao Governo e o preço de exercício representa o valor pago pela CONAB (valor preestabelecido na data de vencimento do contrato). De acordo com CONAB (2009b), os produtos contemplados são os mesmos amparados pela PGPM e as especificações das unidades de medida desses Contratos são seis toneladas/contrato para o café e 27 toneladas/contrato para os demais produtos. No Anexo 1 é possível observar o fluxograma de funcionamento dos COV. 
A sustentação dos preços agrícolas catarinenses no período 1997-20 I I: uma análise dos contratos de opção de venda (COV)

\section{A SUSTENTAÇÃO DOS PREÇOS AGRÍCOLAS NO BRASIL E EM SANTA CATARINA}

Na Tabela 1 é apresentado o acompanhamento dos COV de produtos agrícolas lançados pelo Governo Federal no período 1997-2004. Nesse período foram ofertados Contratos para os produtos algodão, arroz, café, milho, sorgo e trigo, sendo vendidos 404.736 Contratos. Desse total, apenas 151.122 foram efetivamente realizados, ou seja, apenas 37,34\% dos Contratos.

Tabela 1: Acompanhamento dos COV de produtos agrícolas lançados pelo Governo Federal no Brasil no período 1997-2004 - vendidos e exercidos por ano e por produto

\begin{tabular}{c|c|c|c|c}
\hline \multicolumn{2}{c}{ DETALHAMENTO } & \multicolumn{1}{c}{ CONTRATOS } & \multicolumn{1}{c}{ CONTRATOS } & PARTICIPAÇÃO (\%) \\
\hline ANO & PRODUTOS & VENDIDOS (A) & EXERCIDOS (B) & (B/A) \\
\hline $\mathbf{1 9 9 7}$ & Total Milho & 37.823 & 9.151 & 24,19 \\
\hline \multirow{3}{*}{1999} & Total Algodão & 10.246 & 3.515 & 34,31 \\
\cline { 2 - 5 } & Total Arroz & 19.218 & 15.236 & 79,28 \\
\cline { 2 - 5 } & Total Milho & 13.097 & 225 & 1,72 \\
\hline \multirow{4}{*}{$\mathbf{2 0 0 0}$} & Total Algodão & 2.483 & 969 & 39,03 \\
\cline { 2 - 5 } & Total Arroz & 30.877 & 28.325 & 91,73 \\
\cline { 2 - 5 } & Total Milho & 5.698 & 265 & 4,65 \\
\cline { 2 - 5 } & Total Trigo & 10.440 & 795 & 7,61 \\
\hline \multirow{2}{*}{$\mathbf{2 0 0 1}$} & Total Milho & 78.968 & 22.334 & 28,28 \\
\cline { 2 - 5 } & Total Arroz & 22.648 & 164 & 0,72 \\
\hline \multirow{3}{*}{$\mathbf{2 0 0 3}$} & Total Milho & 66.092 & 1.705 & 2,58 \\
\cline { 2 - 5 } & Total Café & 20.245 & 9.809 & 48,45 \\
\cline { 2 - 5 } & Total Milho & 64.261 & 51.253 & 79,76 \\
\cline { 2 - 5 } & Total Sorgo & 3.465 & 1.756 & - \\
\hline \multirow{2}{2004}{} & Total Trigo & 19.175 & - & $29,31 *$ \\
\hline TOTAl Trigo & - & 5.620 & $\mathbf{3 7 , 3 4}$ \\
\hline
\end{tabular}

Fonte: Elaborado pelos autores a partir de CONAB (2010).

Notas: Algodão: em 1999, um contrato equivalia a 12,75 toneladas e, a partir de 2000, um contrato passou a equivaler a 27 toneladas. Arroz, milho, sorgo e trigo: um contrato equivale a 27 toneladas. Ano de 1998: não ocorreram negociações com os COV nesse ano. Ano de 2002: dos 319.613 Contratos de milho ofertados, 117.044 venciam em 2002 e 202.569 venciam em 2003. Dos 66.092 Contratos vendidos em 2002, 53.754 venciam em 2003, não tendo havido exercício para esses Contratos em 2003. (*) Ano de 2003: os Contratos ofertados e vendidos em 2003 tinham vencimento para 2004, razão pela qual constam como exercidos em 2004. 
No Gráfico 1 é possível observar que a maior concentração de Contratos exercidos pelos produtores ou cooperativas ocorre com os produtos milho e arroz, que são, segundo Pereira (2004), os produtos que apresentam os maiores volumes de estocagem por parte do Governo Federal. Os Contratos de opção para a comercialização do trigo passaram a ser disponibilizados pelo Governo somente a partir da safra agrícola 2000/2001. Em relação ao algodão, pode-se afirmar que a política de comercialização foi pouco ativa durante o período de análise.

Gráfico 1: Participação dos produtos (em toneladas) no total de Contratos exercidos pelos produtores no Brasil no período 1997-2004

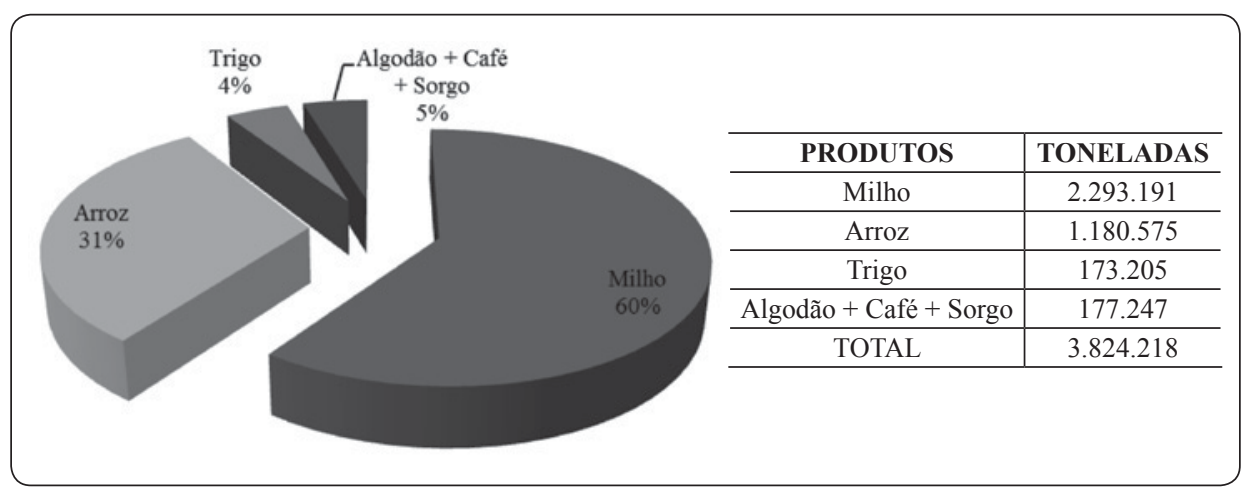

Fonte: Elaborado pelos autores a partir de CONAB (2010).

O milho aparece como principal produto, de acordo com Campos (2007, p. 323), pois

[...] há necessidade de reter estoques suficientes para que seja possível regularizar a oferta doméstica em anos de redução da produção, garantindo a sustentação dos preços internos e diminuindo sua volatilidade. Além disso, a sustentação de preços é estratégica também para a criação de excedentes exportáveis e para a redução na instabilidade financeira dos produtores.

Em relação aos estados que participam das negociações dos COV, identifica-se no Quadro 2 que há uma concentração de Contratos exercidos, principalmente, nas regiões Centro-Oeste, Sul e Sudeste. 
A sustentação dos preços agrícolas catarinenses no período 1997-20 I I: uma análise dos contratos de opção de venda (COV)

Quadro 2: Acompanhamento de COV de produtos agrícolas lançados pelo Governo Federal no Brasil no período 1997-2004 - exercidos por estado e por produto

\begin{tabular}{|c|c|c|}
\hline ANO & ESTADOS & PRODUTOS \\
\hline 1997 & GO - MS - MT - PR & Milho \\
\hline 1999 & BA - GO - MG - MS - MT - PR - SP - RS & Algodão - Arroz - Milho \\
\hline 2000 & BA - GO - MG - MS - MT - PR - SP - RS - SC & Algodão - Arroz - Milho - Trigo \\
\hline 2001 & GO - MS - PR & Milho \\
\hline 2002 & GO - MS -RS & Arroz - Milho \\
\hline 2003 & BA - ES - GO - MG - MS - MT - PR - RJ - SP & Café Arábica - Milho - Sorgo \\
\hline 2004 & --- & Trigo \\
\hline
\end{tabular}

Fonte: Elaborado pelos autores a partir de CONAB (2010).

Nota: Ano de 2003: os Contratos ofertados e vendidos em 2003 tinham vencimento para 2004, razão pela qual constam como exercidos em 2004.

Em relação ao período 1997-2004, portanto, a maior participação de produto, dentre os Contratos exercidos pelos produtores, foi do milho, totalizando $59 \%$ do total, justificados pelos estoques e por estratégias de precificação no mercado. Já dentre os estados negociantes dos COV, a maior concentração aparece nas regiões Centro-Oeste, Sul e Sudeste, sendo que o estado de Santa Catarina teve participação somente no ano de 2000, juntamente aos estados que comercializaram, neste ano, algodão, arroz, milho e trigo.

Cruz e Teixeira (2006) analisaram os COV no período de 1997 a 2005, identificando que os mercados de milho e de arroz obtiveram os maiores volumes de compra desse tipo de instrumento de comercialização agrícola. A política de sustentação de preços agrícolas mostrou-se eficaz no período analisado, pois permitiu estabilidade de preços, com exceção no caso do milho, onde as oscilações de oferta interna diminuíram a eficácia do instrumento.

A Tabela 2 apresenta o acompanhamento dos COV de produtos agrícolas lançados pelo Governo Federal no período 2005-2009. Nesse período foram ofertados 375.768 Contratos para os produtos arroz, milho, trigo e feijão, sendo vendidos 284.571 Contratos, ou seja, 75,73\% dos Contratos. Desse total, $49,20 \%$ e $35,05 \%$ dos Contratos foram vendidos, respectivamente, em 2009 e 2008. 
Tabela 2: Acompanhamento de COV de produtos agrícolas lançados pelo Governo Federal no Brasil no período 2005-2009 - ofertados e vendidos por ano, por produto e por estado

\begin{tabular}{|c|c|c|c|c|c|}
\hline \multicolumn{3}{|c|}{ DETALHAMENTO } & OFERTADOS & VENDIDOS & PARTICIPAÇÃO (\%) \\
\hline ANO & PRODUTOS & UF & NÚMERO (A) & NÚMERO (B) & $(\mathbf{B} / \mathbf{A})$ \\
\hline \multirow{6}{*}{2005} & \multirow{2}{*}{ Arroz em Casca } & RS & 10.740 & 10.740 & 100,00 \\
\hline & & SC & 2.224 & 2.224 & 100,00 \\
\hline & \multicolumn{2}{|l|}{ Total Arroz } & 12.964 & 12.964 & 100,00 \\
\hline & Trigo em Grãos & $\mathrm{RS}$ & 72 & 72 & 100,00 \\
\hline & \multicolumn{2}{|l|}{ Total Trigo } & 72 & 72 & 100,00 \\
\hline & \multicolumn{2}{|l|}{ Total 2005} & 13.036 & $\mathbf{1 3 . 0 3 6}$ & 100,00 \\
\hline \multirow{4}{*}{2007} & \multirow{2}{*}{ Arroz em Casca } & RS & 30.344 & 29.034 & 95,68 \\
\hline & & SC & 6.097 & 2.733 & 44,83 \\
\hline & \multicolumn{2}{|l|}{ Total Arroz } & 36.441 & 31.767 & 87,17 \\
\hline & \multicolumn{2}{|l|}{ Total 2007} & 36.441 & 31.767 & 87,17 \\
\hline \multirow{15}{*}{2008} & \multirow{3}{*}{ Feijão } & GO & 667 & 0 & 0,00 \\
\hline & & MG & 722 & 0 & 0,00 \\
\hline & & SP & 463 & 0 & 0,00 \\
\hline & \multicolumn{2}{|l|}{ Total Feijão } & 1.852 & 0 & 0,00 \\
\hline & Milho em Grãos & MT & 108.505 & 58.909 & 54,29 \\
\hline & \multicolumn{2}{|l|}{ Total Milho } & 108.505 & 58.909 & 54,29 \\
\hline & \multirow{7}{*}{ Trigo em Grãos } & GO & 675 & 75 & 11,11 \\
\hline & & MG & 1.530 & 143 & 9,35 \\
\hline & & MS & 1.265 & 609 & 48,14 \\
\hline & & PR & 22.426 & 15.580 & 69,47 \\
\hline & & $\mathrm{RS}$ & 20.515 & 20.515 & 100,00 \\
\hline & & SC & 1.400 & 1.400 & 100,00 \\
\hline & & SP & 5.490 & 2.537 & 46,21 \\
\hline & \multicolumn{2}{|l|}{ Total Trigo } & 53.301 & 40.859 & 76,66 \\
\hline & \multicolumn{2}{|l|}{ Total 2008} & 163.658 & 99.768 & 60,96 \\
\hline \multirow{11}{*}{2009} & \multirow{6}{*}{ Milho em Grãos } & GO & 19.572 & 19.572 & 100,00 \\
\hline & & MG & 5.550 & 4.795 & 86,40 \\
\hline & & MS & 33.852 & 33.111 & 97,81 \\
\hline & & MT & 48.668 & 45.963 & 94,44 \\
\hline & & PR & 22.112 & 11.839 & 53,54 \\
\hline & & $\mathrm{RO}$ & 400 & 400 & 100,00 \\
\hline & \multicolumn{2}{|l|}{ Total Milho } & 130.154 & 115.680 & 88,88 \\
\hline & \multirow{2}{*}{ Arroz em Casca } & RS & 29.411 & 23.597 & 80,23 \\
\hline & & SC & 3.068 & 723 & 23,57 \\
\hline & \multicolumn{2}{|l|}{ Total Arroz } & 32.479 & 24.320 & 74,88 \\
\hline & \multicolumn{2}{|l|}{ Total 2009} & 162.633 & 140.000 & 86,08 \\
\hline \multicolumn{3}{|c|}{ TOTAL PRODUTOS } & 375.768 & 284.571 & 75,73 \\
\hline
\end{tabular}

Fonte: Elaborado pelos autores a partir de CONAB (2010). 
A sustentação dos preços agrícolas catarinenses no período 1997-20 I I: uma análise dos contratos de opção de venda (COV)

No período 2005-2009, observa-se que os estados da região Sul e da região Centro-Oeste concentraram a maior parte dos Contratos vendidos (Quadro 3).

Quadro 3: Acompanhamento de COV de produtos agrícolas lançados pelo Governo Federal no Brasil no período 2005-2009 - vendidos por estado e por produto

\begin{tabular}{|c|c|c|}
\hline ANO & ESTADOS & PRODUTOS \\
\hline 2005 & $\mathrm{RS}-$ SC & Arroz - Trigo \\
\hline 2007 & $\mathrm{RS}-$ SC & Arroz \\
\hline 2008 & $\mathrm{GO}-\mathrm{MG}-\mathrm{SP}-\mathrm{MT}-\mathrm{MS}-\mathrm{PR}-\mathrm{RS}-\mathbf{S C}$ & Milho - Trigo \\
\hline 2009 & $\mathrm{GO}-\mathrm{MG}-\mathrm{MS}-\mathrm{MT}-\mathrm{PR}-\mathrm{RO}-\mathrm{RS}-\mathbf{S C}$ & Milho - Arroz \\
\hline
\end{tabular}

Fonte: Elaborado pelos autores a partir de CONAB (2010).

A maior concentração de Contratos vendidos pelo Governo Federal ocorre com o milho, com $61 \%$ do total, seguido por arroz e trigo, como é possível observar no Gráfico 2.

Gráfico 2: Participação dos produtos no total de Contratos vendidos pelo Governo Federal no Brasil no período 2005-2009

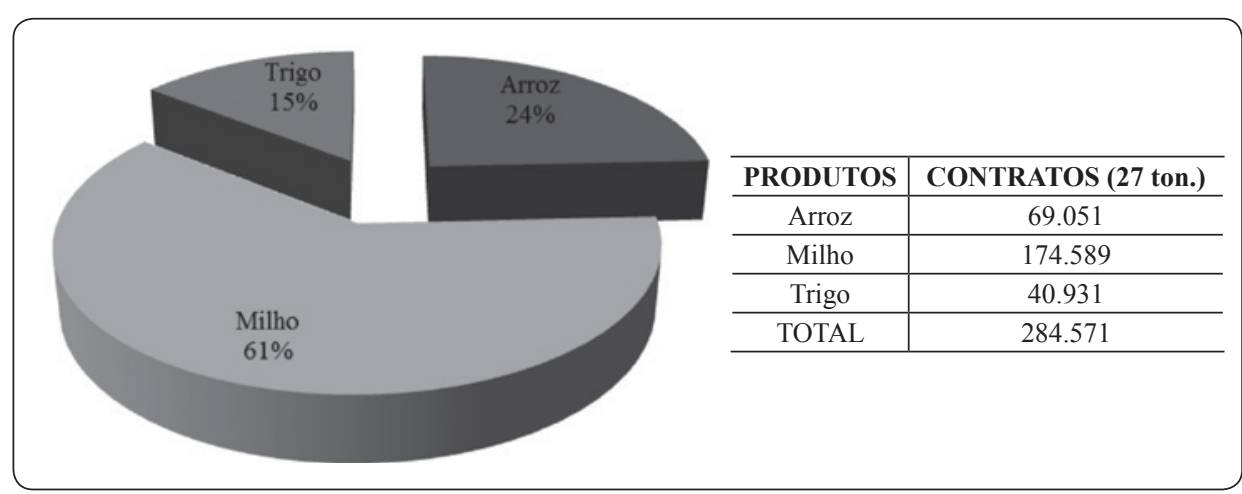

Fonte: Elaborado pelos autores a partir de CONAB (2010).

Em relação ao período 2005-2009, observa-se que o estado catarinense operou na totalidade de compra e venda dos COV de arroz em casca que foram ofertados pelo Governo Federal para este estado, no ano de 2005, atingindo $17,16 \%$ do total do arroz neste mesmo ano. No ano de 2007, Santa 
Catarina comprou 2.733 dos 6.097 Contratos ofertados pelo Governo Federal ao estado neste ano, também de arroz em casca. Em 2008, o estado catarinense comprou $100 \%$ dos Contratos ofertados de trigo em grãos, a saber, o número de 1.400 Contratos, o que significou 2,62\% do total de trigo daquele ano. Já no ano de 2009, a negociação deste estado voltou a ser com arroz em casca, entretanto, com volumes pouco significativos se comparados ao total ofertado pelo Governo no ano em questão. O número ofertado foi de 32.479 Contratos e, deste total, 3.068 para Santa Catarina, que comprou apenas 723, ou seja, 23,57\%. Este volume foi bem abaixo do Rio Grande do Sul, que comprou $80,23 \%$ do total a ele ofertado. Segundo CONAB (2010), nos anos de 2005 a 2009, os estados que se destacaram no número de Contratos vendidos estavam localizados nas regiões região Sul e Centro-Oeste, onde Santa Catarina esteve presente em todo o período na negociação de diferentes produtos agrícolas, sendo eles, o arroz, o trigo e o milho.

A Tabela 3 apresenta o acompanhamento dos COV de produtos agrícolas lançados pelo Governo Federal no período 2010-2011.

Tabela 3: Acompanhamento das aquisições dos COV de produtos agrícolas lançados pelo Governo Federal no Brasil no período 2010-2011 - em valor $(\mathrm{R} \$)$ por ano, por produto e por estado

\begin{tabular}{|c|c|c|c|c|c|}
\hline \multirow{2}{*}{ UF } & \multicolumn{3}{|c|}{2010} & \multicolumn{2}{|c|}{2011} \\
\hline & CAFÉ & MILHO & TOTAL & ARROZ & TOTAL \\
\hline BA & $2.564 .748,00$ & - & $2.564 .748,00$ & - & - \\
\hline ES & $1.613 .820,00$ & - & $1.613 .820,00$ & - & - \\
\hline MG & $312.399 .854,45$ & - & $312.399 .854,45$ & - & - \\
\hline MS & - & $110.214,00$ & $110.214,00$ & - & - \\
\hline MT & - & $535.410,00$ & $535.410,00$ & - & - \\
\hline PR & $6.496 .165,74$ & - & $6.496 .165,74$ & - & - \\
\hline RS & - & - & - & $119.865 .814,20$ & $119.865 .814,20$ \\
\hline SC & - & - & - & $6.020 .460,00$ & $6.020 .460,00$ \\
\hline SP & $31.545 .111,10$ & - & $31.545 .111,10$ & - & - \\
\hline TOTAL & $354.619 .699,29$ & $645.624,00$ & $355.265 .323,29$ & $125.886 .274,20$ & 125.886.274,20 \\
\hline
\end{tabular}

Fonte: Elaborado pelos autores a partir de CONAB (2012a). 
A sustentação dos preços agrícolas catarinenses no período 1997-20 I I: uma análise dos contratos de opção de venda (COV)

No ano de 2010, os Contratos ficaram concentrados nos estados de Minas Gerais (café) e de Mato Grosso (milho), sendo que o primeiro absorveu $88 \%$ do valor total das aquisições para o café e o segundo concentrou $83 \%$ dos recursos direcionados para o milho. Em 2011, as aquisições foram direcionadas para o arroz e os estados beneficiados foram Rio Grande do Sul e Santa Catarina, sendo que o primeiro obteve $95 \%$ do valor total das aquisições para esta cultura.

No período 2010-2011, observa-se a participação do estado catarinense somente no ano de 2011, com a aquisição de COV de arroz, atingindo o valor de R \$ 6 milhões, o que significou uma participação de apenas 4,78\% em relação ao valor total (R $\$ 125,9$ milhões), sendo que o restante foi adquirido pelo Rio Grande do Sul.

Em relação ao arroz, na safra de 2010/2011, o Rio Grande do Sul produziu 8,83 milhões de toneladas e Santa Catarina produziu 0,95 milhões de toneladas, considerando um total de 13,35 milhões de toneladas em todo o país. Os dois estados são os maiores produtores de arroz do Brasil e respondem por mais de 73\% da produção nacional (EPAGRI, 2012a). Com a queda dos preços da saca de arroz nos anos de 2010 e de 2011, ambos os estados receberam recursos do Governo Federal, dentre os quais $\mathrm{R} \$ 125,9$ milhões em aquisições do Governo Federal de COV.

O indicador de preços de arroz de ESALQ/Bolsa Brasileira de Mercadorias-BM\&Fbovespa (2012) demonstra que o preço da saca iniciou 2010 acima de $\mathrm{R} \$ 32,00$ e terminou o ano abaixo de R \$25,00. Em abril de 2011, já estava em R $\$ 19,33$, sendo registrados então os preços mais baixos nos últimos 11 anos nos dois meses seguintes. Também em 2011, o preço esteve bastante abaixo dos preços de 2010, principalmente no segundo trimestre do ano, em que a diferença foi superior a $\mathrm{R} \$ 7,00$, conforme demonstrado no Gráfico 3. 
Gráfico 3: Preços da saca de $50 \mathrm{~kg}$ de arroz $(\mathrm{R} \$)$ nos estados de Santa Catarina e do Rio Grande do Sul no período 2010-2011

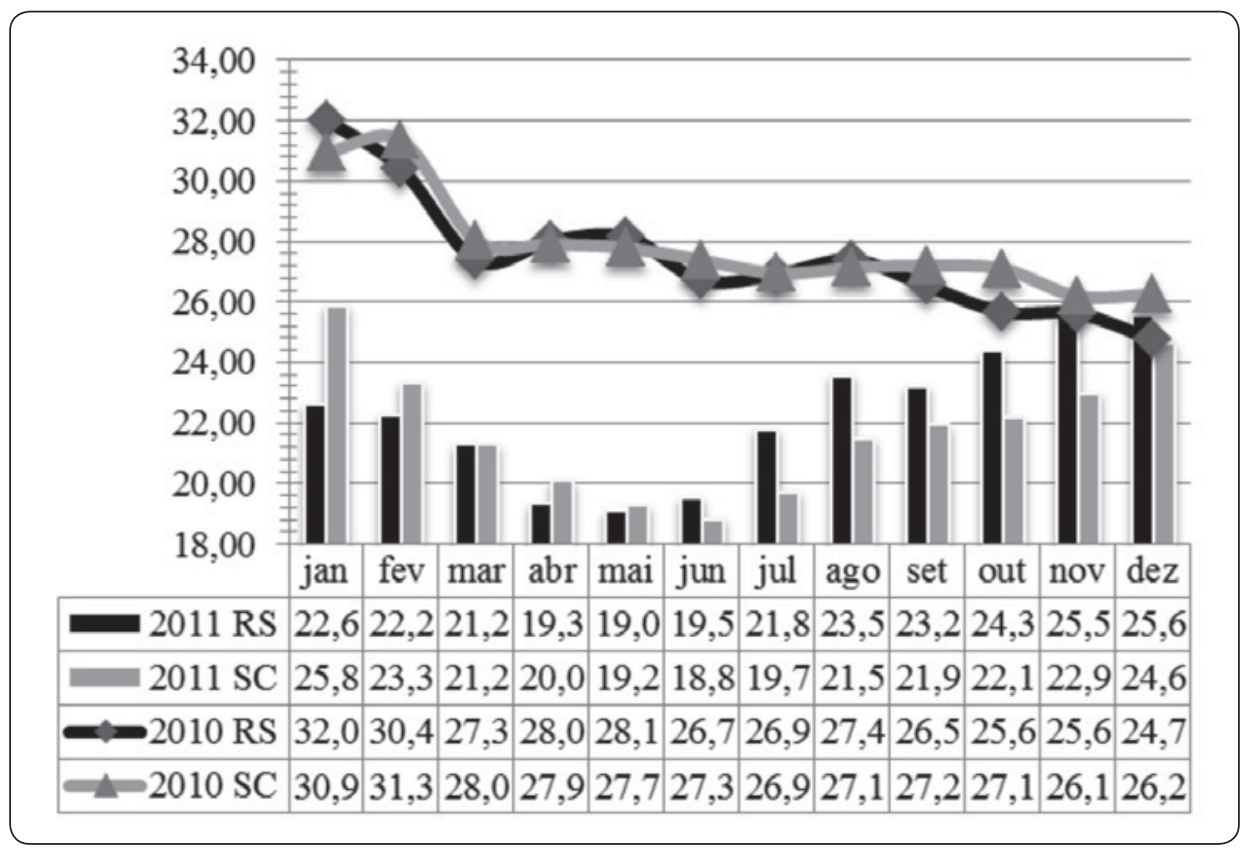

Fonte: ESALQ/Bolsa Brasileira de Mercadorias-BM\&Fbovespa (2012) para o estado do Rio Grande do Sul e Agrolink (2012) para o estado de Santa Catarina.

Nota: Preço para saca de $50 \mathrm{~kg}$, tipo 1, 58/10, à vista.

A baixa dos preços é reflexo da safra cheia em 2010/2011 nos países do Mercado Comum do Sul (MERCOSUL), do real valorizado, do aumento na produção nacional nesta mesma safra, da estabilidade do consumo doméstico e do aumento dos estoques do produto. Também são fatores críticos para a próxima safra os preços internacionais, a taxa de câmbio valorizada e a quantidade de produção interna (CMN, 2012; CONAB, 2012c, EPAGRI, 2012b).

A situação dos preços em queda - e abaixo do mínimo de $\mathrm{R} \$ 25,80$ estipulado pelo Governo para o ano de 2011 - causou uma crise sem precedentes entre os orizicultores, pois estes possuem alta participação dos custos variáveis na produção ( $85 \%$ do custo total), tiveram aumento de seu endividamento nos últimos anos e o preço dos insumos não estão caindo como ocorria em outras crises no setor (EPAGRI, 2012a). Em razão disso, o Governo Federal interveio e, no dia 2 de junho de 2011 tiveram inicio os 
A sustentação dos preços agrícolas catarinenses no período 1997-20 I I: uma análise dos contratos de opção de venda (COV)

leilões de COV para o arroz, exclusivamente, nos estados do Rio Grande do Sul e de Santa Catarina, os quais foram normatizados pela Portaria Interministerial MAPA/MF 254, de 17 de maio de 2011. Nesta Portaria se estabeleceu o preço de exercício de $\mathrm{R} \$ 29,00 / 50 \mathrm{~kg}$, sendo que cada Contrato é para 27 toneladas de arroz. Para os COV, foi disponibilizado um volume de recursos de até $\mathrm{R} \$ 300$ milhões oriundos das Operações Oficiais de Créditos.

Foram feitos então dois leilões. O primeiro, no dia 02 de junho de 2011, no qual foram ofertados 7.408 Contratos aos produtores, com valor de abertura do leilão de $\mathrm{R} \$ 78,30$ para cada Contrato, o que equivale a $\mathrm{R} \$$ 0,145 por saca de $50 \mathrm{~kg}$. No lote do Rio Grande do Sul houve grande disputa e o prêmio de fechamento foi de $\mathrm{R} \$ 1.125,00$, totalizando $\mathrm{R} \$ 7,5$ milhões, enquanto no lote de Santa Catarina os Contratos fecharam com preço igual ao de abertura ( $\mathrm{R} \$ 78,30)$, resultando num total negociado de $\mathrm{R} \$ 58.020,30$ (CONAB, 2012a). Um segundo leilão de COV realizou-se em 16 de junho do mesmo ano, onde foram ofertados 10.000 Contratos de 27 toneladas para o Rio Grande do Sul e 1.111 Contratos para o estado catarinense. No estado gaúcho, o preço por Contrato fechou em $\mathrm{R} \$ 701,00$, enquanto em Santa Catarina o fechamento, novamente, se deu no prêmio de abertura (R\$ 78,30) (CONAB, 2012b).

Com este novo leilão, esgotaram-se as autorizações de lançamento de Contratos por parte da CONAB, apesar de os preços de mercado ainda se encontrarem abaixo do mínimo fixado pelo Governo. Deste modo, em 18 de julho de 2011, foi firmada a Portaria Interministerial 357, que autoriza a CONAB a lançar novos COV, até o limite de $\mathrm{R} \$ 300$ milhões, para aquisição de arroz em casca, sendo cada contrato de 27 toneladas. Nesta Portaria foi incluído o Paraná e os preços de exercício variavam de acordo com o tipo do arroz e o estado em que seria feito o leilão. Após esta Portaria, foram feitos outros quatro leilões nos meses de agosto e setembro de 2011.

$\mathrm{Na}$ Tabela 4 é apresentada a relação dos leilões realizados, bem como a quantidade de Contratos ofertados e a quantidade comercializada (isto é, comprada pelos produtores). É possível averiguar que foram feitos seis leilões de COV em 2011, nos quais foram comercializados 32.852 Contratos no Rio Grande do Sul e 3.169 em Santa Catarina, o que equivale, respectivamente, a 887.004 toneladas e 85.563 toneladas, tendo em conta que cada contrato refere-se a 27 toneladas de arroz. De acordo com CONAB (2012a), o Go- 
verno Federal adquiriu, em 2011, o equivalente a 204.039 toneladas no Rio Grande do Sul e 10.341 toneladas em Santa Catarina, o que corresponde, respectivamente, a $23 \%$ e $12 \%$ do total comercializado durante o ano, sendo que para o Paraná, o Governo não adquiriu nenhum contrato em 2011.

Tabela 4: Acompanhamento de COV lançados pelo Governo Federal em 2011 - ofertados pelo Governo Federal e comprados pelo produtor, por UF e por data de lançamento

\begin{tabular}{c|c|c|c|c|c|c|c|c}
\hline \multicolumn{1}{c}{ DETALHAMENTO } \\
\hline UF & NEGÓCIO & $\mathbf{0 2 . 0 6 . 1 1}$ & $\mathbf{1 6 . 0 6 . 1 1}$ & $\mathbf{1 1 . 0 8 . 1 1}$ & $\mathbf{2 5 . 0 8 . 1 1}$ & $\mathbf{0 9 . 0 9 . 1 1}$ & $\mathbf{2 2 . 0 9 . 1 1}$ & TOTAL \\
\hline \multirow{2}{*}{ PR } & Oferta & - & - & 185 & 92 & 92 & 37 & 406 \\
\cline { 2 - 9 } & Compra & - & - & 160 & 92 & 90 & 37 & 379 \\
\hline \multirow{2}{*}{ RS } & Oferta & 6.667 & 10.000 & 8.149 & 4.075 & 4.075 & 3.889 & 36.855 \\
\cline { 2 - 9 } & Compra & 6.667 & 10.000 & 7.291 & 4.075 & 3.369 & 1.450 & 32.852 \\
\hline \multirow{2}{*}{ SC } & Oferta & 741 & 1.111 & 926 & 463 & 463 & 260 & 3.964 \\
\cline { 2 - 9 } & Compra & 741 & 1.111 & 926 & 285 & 63 & 43 & 3.169 \\
\hline
\end{tabular}

Fonte: Elaborado pelos autores a partir de CONAB (2012b; 2012c; 2012d; 2012e; 2012f).

Verifica-se, então, que os leilões de COV atuaram como um dos instrumentos da PGPM, tendo em conta que houve um aumento dos preços da saca de arroz após os leilões de COV realizados em junho, em agosto e em setembro. Outrossim, como os Contratos tinham vencimento no final de novembro ou final de dezembro, eles balizaram os preços de mercado ao menos até o vencimento, contribuindo para que os mesmos chegassem ao preço mínimo de R \$25,80 no final de dezembro de 2011.

Por fim, a estabilização macroeconômica obtida após o Plano Real e a criação de novos instrumentos de política agrícola, como os COV, permitiram uma maior estabilidade dos preços (menor volatilidade) e das receitas no mercado agrícola e geraram uma maior segurança para o setor. Contudo, deve-se ressaltar que as oscilações de oferta interna podem causar a redução da eficácia desses mecanismos de sustentação dos preços.

\section{CONSIDERAÇÕES FINAIS}

A atual conjuntura macroeconômica enfrentada pelo Governo Federal, maior abertura comercial e restrições de recursos, tornou incompatível a associação de uma política agrícola com o dispêndio imediato de recursos 
A sustentação dos preços agrícolas catarinenses no período 1997-20 I I: uma análise dos contratos de opção de venda (COV)

do Tesouro Nacional. Dessa forma, ao longo da década de 1990 ocorreram reformas na política agrícola brasileira, como a não contratação de EGFCOV a partir da safra agrícola de 1996/1997 e a criação de novos instrumentos de garantia de preços coerentes com a economia aberta, como os COV que buscam a sustentação dos preços agrícolas.

A definição do volume de COV negociados é estabelecida pela CONAB em função do comportamento do mercado e da própria disponibilidade de recursos. A atuação do Governo Federal, por meio do lançamento de COV ou da própria PGPM, ocorre quando é identificado que os preços recebidos pelos produtores rurais estão sendo inferiores aos preços mínimos. O objetivo é igualar os preços de mercado aos preços mínimos, considerando o limite disponível de recursos para o funcionamento desta política.

Um aspecto importante desse instrumento é que o produtor não realiza a venda imediata ao Governo Federal, mas procura melhores preços no mercado. Ou seja, os COV atuam como um seguro contra a oscilação dos preços agrícolas, já que a variabilidade de preços é um dos fatores responsáveis pela dificuldade de planejamento nos âmbitos da produção e do abastecimento do mercado. A adoção desse mecanismo de compra da PGPM busca reduzir os riscos na atividade agrícola, permitindo a expansão de investimentos, principalmente, nas culturas ligadas ao agronegócio.

Concluiu-se que, no período de análise, o estado de Santa Catarina esteve presente nas negociações de COV ofertados pelo Governo Federal, entretanto, com valores não tão expressivos, se comparados com a participação de outros estados, em produtos agrícolas iguais ou diferenciados. Como observado no período 1997-2004, onde o estado catarinense teve participação somente no ano de 2000. Nos anos de 2005 e 2007 participou do processo com o arroz em casca, sendo que no ano de 2005 negociou todos os COV ofertados pelo Governo Federal. Já no ano de 2008, o produto negociado foi o trigo em grãos, $100 \%$, correspondente ao número de 1.400 Contratos e equivalente a 2,62\% do total ofertado naquele ano. Em 2009 e 2011, Santa Catarina novamente negociou Contratos de arroz, em porcentagens de 23,57\% e de $4,78 \%$, respectivamente, em relação ao total, demonstrando com estes números uma baixa participação nos COV deste estado.

Em 2011, 3.964 Contratos foram disponibilizados pelo Governo Federal para Santa Catarina, dos quais 3.169 foram comprados pelos produtores ou 
cooperativas. Isto equivale a 85.563 toneladas de arroz com preço segurado pelo Governo. Observa-se também uma relação positiva entre o lançamento de leilões de $\mathrm{COV}$ e a melhoria nos preços, pois a partir do primeiro leilão, em 02 de junho de 2011, iniciou-se também um aumento progressivo dos preços até dezembro. No caso de Santa Catarina, o preço em junho estava, na média do mês, em R $\$ 18,84$ a saca de $50 \mathrm{~kg}$, enquanto em dezembro esteve em $\mathrm{R} \$ 24,63$, próximo do mínimo de $\mathrm{R} \$ 25,80$, determinado pelo Governo. Em comparação ao ano anterior, o preço em junho estava em $\mathrm{R} \$ 27,79$ e em dezembro ficou em R $\$ 26,26$. Deste modo, se verificam os COV como um instrumento da PGPM capaz de assegurar a manutenção dos preços.

\title{
MINIMUM PRICE GUARANTEE POLICY FOR AGRICULTUR- AL PRODUCTS OF SANTA CATARINA STATE, FROM 1997-2011: AN ANALYSIS OF COMMODITY OPTIONS MARKETS (COM) POLICY INSTRUMENTS
}

\begin{abstract}
This paper aims at analyzing Commodity Options Markets (COM) operated for Federal Government to support the Minimum Price Guarantee Policy (MPGP) in the state of Santa Catarina, during the period between 1997 and 2011. The results show that, in the period examined, the state played an active role in the negotiation of the COM supplied by the federal government in almost all years, despite having smaller values when compared with other Brazilian states. In relation to rice, it was possible to note that the COM was a MPGP instrument capable of assuring stable prices.
\end{abstract}

Keywords: Commodity Options Markets; Minimum Price Policy; Agricultural Prices.

JEL Classification: Q1; Q11; Q18. 
A sustentação dos preços agrícolas catarinenses no período 1997-20 I I: uma análise dos contratos de opção de venda (COV)

\section{REFERÊNCIAS}

ADAMI, Andréia Cristina de Oliveira. Contratos de Opção: análise do potencial de sustentação de preços para o mercado de arroz. 2005. Dissertação (Mestrado em Economia Aplicada) - Escola Superior de Agricultura Luiz de Queiroz, Universidade de São Paulo, Piracicaba.

AGROLINK. Cotações: arroz irrigado em casca sc 50kg - UF SC. Disponível em: http://www.agrolink.com.br/cotacoes/graos/arroz. Acesso em: 02 mar. 2012.

BLECHER, Bruno. Collor quer Estado fora do mercado agrícola. Folha de São Paulo, São Paulo, Agrofolha, p.G.32, jan. 1990.

CAMPOS, Kilmer Coelho. Análise da volatilidade de preços de produtos agropecuários no Brasil. Revista de Economia e Agronegócio, Viçosa, v. 5, n. 3, p. 303-328, 2007.

CEZAR, Nilza M. A safra agrícola e o Plano Collor. Indicadores Econômicos FEE, Porto Alegre, v.18, n. 2, p.34-51, ago. 1990.

CMN - Conselho Monetário Nacional. Votos agrícolas: reunião CMN de 28 de abril de 2011. Disponível em http://www.fazenda.gov.br/spe. Acesso em: 20 fev. 2012.

CONAB - Companhia Nacional de Abastecimento. Avisos de venda de Contrato de Opção de arroz em casca. Disponível em: http://www.conab. gov.br. Acesso em: 22 fev. $2012 b$.

CONAB - Companhia Nacional de Abastecimento. Cartilha do Contrato de Opção de Venda. Disponível em: http:/www.conab.gov.br/conabweb/ download/comercializacao/arq_link_menu/cartilhacontratoopcaovenda.doc. Acesso em: 07 set. 2009a.

CONAB - Companhia Nacional de Abastecimento. Comercialização. Disponível em: http://www.conab.gov.br/conabweb/index.php?PAG=1. Acesso em: 20 mar. 2010. 
Angélica Massuquetti • Marilise Dorneles Spat • Pedro Henrique de Morais Campetti Juliano Luiz Koch • Rafaela Lauffer Ostermann Tamiosso

CONAB - Companhia Nacional de Abastecimento. Comercialização. Disponível em: http://www.conab.gov.br/conabweb/index.php?PAG=1. Acesso em: 16 fev. 2012a.

CONAB - Companhia Nacional de Abastecimento. Comunicado CONAB/ MOC No 027, de 21/10/2005. Disponível em: http://www.conab.gov.br/ conabweb/download/moc/titulos/T27.pdf. Acesso em: 28 set. 2009 b.

CONAB - Companhia Nacional de Abastecimento. Conjuntura semanal: arroz - período: 30.05 a 03.06.2011. Disponível em: http://www.conab.gov. br/conteudos.php? $\mathrm{a}=527 \& \mathrm{t}=2$. Acesso em: $20 \mathrm{fev}$. $2012 \mathrm{c}$.

CONAB - Companhia Nacional de Abastecimento. Conjuntura semanal: arroz - período: 13 a 17.06.2011. Disponível em: http://www.conab.gov.br/ conteudos.php?a=527\&t=2. Acesso em: 20 fev. 2012 d.

CONAB - Companhia Nacional de Abastecimento. Estudos de prospecção de mercado: safra 2011/2012. Disponível em: http://www.conab.gov.br. Acesso em: 22 fev. 2012e.

CONAB - Companhia Nacional de Abastecimento. Relação dos adquirentes de COV. Disponível em: http://www.conab.gov.br. Acesso em: 22 fev. $2012 f$.

CRUZ, Aline Cristina da; TEIXEIRA, Erly Cardoso. Desempenho da política de garantia preços via contratos de opção de venda e prêmios para escoamento de produto. Revista de Política Agrícola, Brasília, Ano XV, n. 4, p.24-36, out./nov./dez. 2006.

DELGADO, Guilherme C. Uma metodologia para determinação de preços mínimos. Coleção Análise e Pesquisa, Brasília, v.3, p.13-29, 1978.

DUARTE, Adriano R. O custo da política de preços mínimos. Estudos Econômicos, São Paulo, v.17, n. 1, p.5-29, jan./abr. 1987. 
A sustentação dos preços agrícolas catarinenses no período | 997-20 I I: uma análise dos contratos de opção de venda (COV)

DURAN, Tulio A. A política de preços mínimos no Brasil. Coleção Análise e Pesquisa, Brasília, v.11, p.141-57, 1978.

EPAGRI - Empresa de Pesquisa Agropecuária e Extensão Rural de Santa Catarina. Síntese Anual da agricultura de Santa Catarina, 2010-2011. Disponível em: http://cepa.epagri.sc.gov.br. Acesso em: 20 fev. 2012a.

EPAGRI - Empresa de Pesquisa Agropecuária e Extensão Rural de Santa Catarina. Situação da rizicultura catarinense. Disponível em: http://cepa. epagri.sc.gov.br. Acesso em: 21 fev. 2012 b.

ESALQ/BOLSA BRASILEIRA DE MERCADORIAS-BM\&FBOVESPA. Indicador arroz em casca. 2012.

FRANCA, Terezinha J. F.; FREITAS, Silene M. Política agrícola: safra 1996/1997. Disponível em: http://www.eu.ansp.br:80/ iea/politica.htm. Acesso em: 18 abr. 1998.

GARCIA, Álvaro A. L.; FÜRSTENAU, Vivian. Agricultura: o dilema da comercialização. Indicadores Econômicos FEE, Porto Alegre, v.20, n. 2, p.30-41, ago. 1992.

GASQUES, José G.; SPOLADOR, Humberto F. S. Taxa de juros e políticas de apoio interno à agricultura. Brasília: IPEA, 2003. (Texto para discussão, 952.).

GASQUES, José G.; VERDE, Carlos M. V. Crescimento da agricultura brasileira e política agrícola nos anos 80. Brasília: IPEA, 1990. (Texto para discussão, 204.)

MASSUQUETTI, A. Contratos de Opção de Venda: um novo instrumento de garantia de preços agrícolas In: CONGRESSO BRASILEIRO DE ECONOMIA E SOCIOLOGIA RURAL, 38., 2000, Rio de Janeiro. Anais ... Brasília: SOBER, 2000. 
MASSUQUETTI, A., KRUTZMANN, V., FALLEIRO, M. P. S., GARCIA, T. F. Análise dos Contratos de Opção de Venda como instrumento de garantia de preços agrícolas no Brasil. In: JORNADAS INTERDISCIPLINARIAS DE ESTUDIOS AGRARIOS Y AGROINDUSTRIALES, 6., 2009, Buenos Aires (Argentina). Anais ... Buenos Aires: CIEA, 2009.

MASSUQUETTI, Angélica. A mudança no padrão de financiamento da agricultura brasileira no período 1965-97. 1998. 222 p. Dissertação (Mestrado em Economia Rural) - Curso de Pós-Graduação em Economia Rural. Universidade Federal do Rio Grande do Sul, RS, 1998.

MOLLO, Maria de L. R. Política de garantia de preços mínimos: uma avaliação. Coleção Análise e Pesquisa, Brasília, v.29, p.11-44, ago. 1983.

OLIVEIRA, João do C. Política de preços mínimos no Brasil. Coleção Análise e Pesquisa, Brasília, v.1, p.3-16, 1977.

PEREIRA, Ana Cibele. Evolução e desempenho da política de Contratos de Opção de Venda para os mercados agrícolas. 2004. Dissertação (Mestrado em Economia Aplicada) - Faculdade de Ciências Econômicas, Universidade Federal de Viçosa, Viçosa.

PINTO, Luís C. G. Notas sobre política agrícola e crédito rural. Campinas, 1980. (não editado.)

PORTO NETO, Arlindo. A política agrícola e a globalização. Revista de Política Agrícola, Brasília, ano 5, n. 4, p.5-11, out./nov./dez. 1996. (Publicação Trimestral.)

PORTO, Célio B. Os contratos de opção como instrumento de política agrícola. Revista de Política Agrícola, Brasília, Ano 5, n. 2, p.7-15, abr./ maio/jun. 1996. (Publicação Trimestral.)

REZENDE, Gervásio C. de. Ajuste externo e agricultura no Brasil, 198186. Revista Brasileira de Economia, Rio de Janeiro, v.42, n. 2, p.101-37, abr./jun. 1988. 
A sustentação dos preços agrícolas catarinenses no período 1997-20 I I: uma análise dos contratos de opção de venda (COV)

SILVA, Paulo R. N. Agricultura: revisão de tendências. Indicadores Econômicos FEE, Porto Alegre, v.19, n. 4, p.50-65, jan. 1992a.

SILVA, Paulo R. N. Alguns aspectos da política agrícola para a safra 1992/1993. Indicadores Econômicos FEE, Porto Alegre, v. 20, n. 3, p.2739, nov. 1992 b.

TURRA, Francisco S. Os novos rumos da política agrícola. Revista de Política Agrícola, Brasília, ano 6, n. 4, p.33-5, out./nov./dez. 1997. (Publicação Trimestral.)

Anexo 1: Fluxograma do Contrato de Opção de Venda

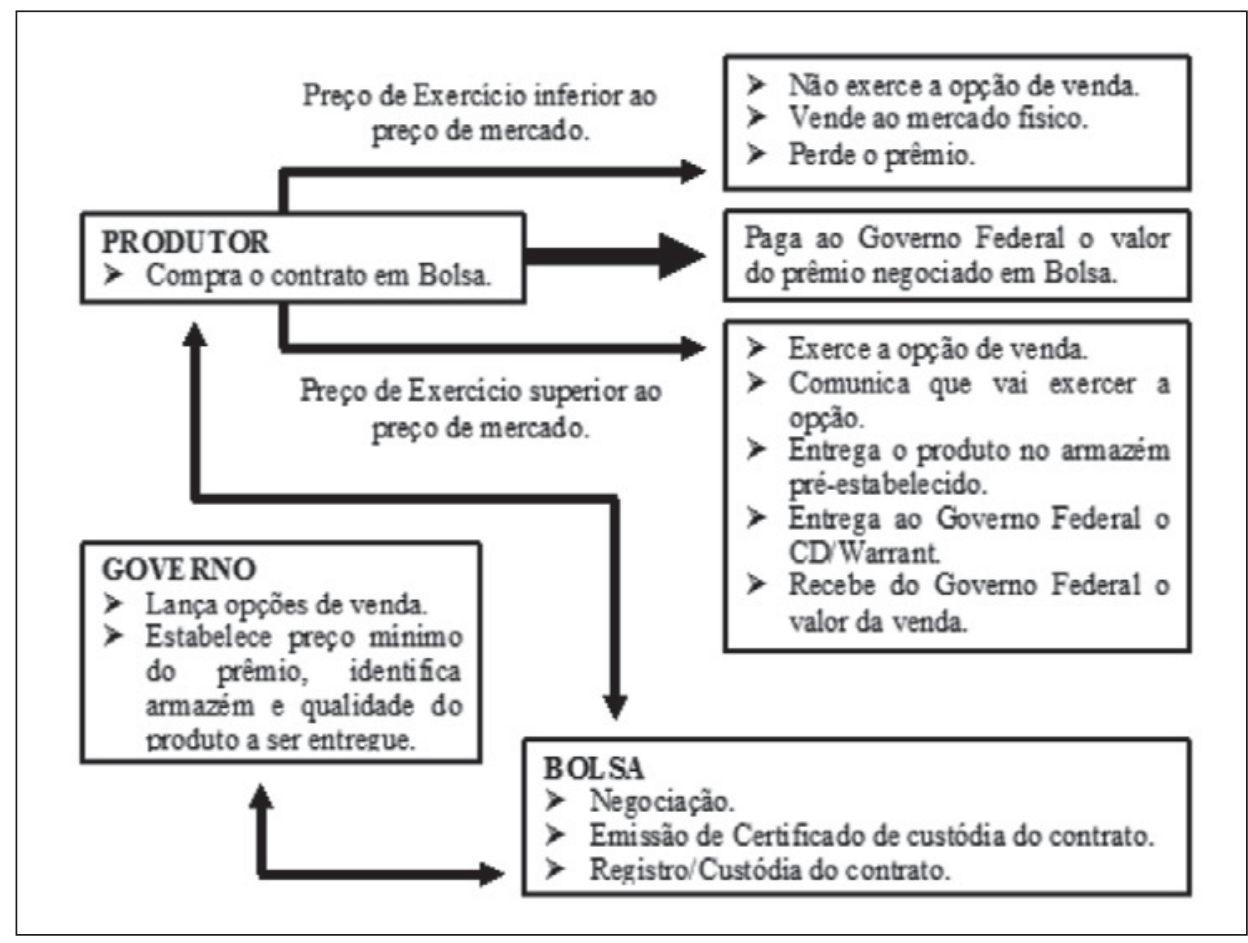

Fonte: Adami (2005, p. 37). 